\title{
Patterns of Hyperglycemia in Patients With Type 2 Diabetes Mellitus With or Without Hypertension, Requiring Emergency Care and Hospitalization
}

\author{
Kameel Mungrue $^{\mathrm{a}, \mathrm{b}}$, Isha Andrea Honore ${ }^{\mathrm{a}}$
}

\begin{abstract}
Background: Hyperglycemia is treatable and preventative cause of both microvascular and macrovascular complications in persons with type 2 diabetes mellitus (T2DM). Hyperglycemia is unequivocally associated with poor outcomes especially in hospitalized patients. The aim of this study therefore is to measure the occurrence of hyperglycemic events particularly in patients with T2DM requiring acute care and subsequent hospitalization with or without hypertension and describe the epidemiological features.
\end{abstract}

Methods: An incident case study design was used, i.e. adult patients ( $\geq 18$ years) with hyperglycemia presenting to the accident and emergency department (AED) of a tertiary teaching hospital from 2011 to 2013 were recruited for the study.

Results: Overall, 350 participants satisfied the criteria for entry into the study. All 350 patients were available for analysis. The pattern of hyperglycemia was predominantly among women, younger rather than older adults, and was a significant association with duration of diabetes and also a significant temporal association.

Conclusions: The patterns shown in the research indicated that hyperglycemia is a concern particularly for the over 40 years old East Indian cohort of the population and as a result programs and initiatives should be directed to this group in order to make a meaningful impact as we seek to reduce the burdens associated with this condition.

Keywords: Type 2 diabetes mellitus; Hyperglycemia; Seasonal variation; Gender disparity

\footnotetext{
Manuscript accepted for publication October 16, 2015

aUniversity of the West Indies, Faculty of Medical Sciences, EWMSC, Mt Hope, Trinidad

${ }^{\mathrm{b} C}$ Corresponding Author: Kameel Mungrue, University of the West Indies, Faculty of Medical Sciences, EWMSC, Mt Hope, Trinidad.

Email:kameel.mungrue@sta.uwi.edu
}

doi: http://dx.doi.org/10.14740/jem313w

\section{Introduction}

Type 2 diabetes mellitus (T2DM) is an independent risk factor for coronary heart disease and stroke, both ranked in the five leading causes of death in Trinidad $[1,2]$. The proportional mortality ratio for T2DM is $15.8 \%$, with an age-adjusted mortality ratio of 118.3 per 100,000 population, the second highest in the world [3,4]. Microvascular and macrovasular complications are the essential contributors to morbidity and mortality in persons with T2DM. In fact, compared with non-diabetic individuals, a person with T2DM has a two- to fourfold increased risk of dying from a myocardial infarction $[1,5]$ or stroke $[5,6]$, and a 10- to 15 -fold increased risk of a lower limb amputation $[7,8]$. It is well established that hyperglycemia is both the major initiator and treatable cause of diabetic microvascular complications (e.g., retinopathy, neuropathy, and nephropathy). Also macrovascular complications such as ischemic heart disease, cerebrovascular disease and peripheral vascular disease are also common in patients with T2DM and contribute significantly to morbidity [9]. Further controlled clinical trials have shown that maintaining a hemoglobin A1c (HbA1c) below $7.0 \%$ can prevent the development and progression of neuropathy, nephropathy and retinopathy in patients with either type 1 or T2DM [9].

Several explanations have been proposed to explain how hyperglycemia can produce the neural and vascular derangements that are distinctly associated with diabetes. These explanations include both the toxic effects of hyperglycemia and its pathophysiological derivatives such as oxidants, hyperosmolarity, or glycation products on tissues directly, as well as the sustained alteration in cell signaling pathways such as changes in phospholipids or kinases induced by the products of glucose metabolism.

Hypertension is common among people with DM [10]. The close association between diabetes and hypertension may be attributed to underlying obesity, insulin resistance, and/ or hyperinsulinemia [10-12]. Hyperglycemia itself may also cause changes in vascular function and structure that lead to hypertension [13, 14]. Furthermore, hypertension is also an important contributor to both the microvascular and the macrovascular complications of diabetes $[15,16]$.

Detailed representative data describing hyperglycemia can have several benefits. Paramount among these benefits is identifying undiagnosed T2DM. In the United States, it is es- 
Table 1. Patients Admitted With Hyperglycemic to the AED by Year, Gender, Age Ethnicity and Marital Status

\begin{tabular}{|c|c|c|c|c|c|c|c|c|c|c|c|c|}
\hline \multirow{2}{*}{$\begin{array}{l}\text { Characteristics } \\
\text { No. of cases }\end{array}$} & \multicolumn{4}{|l|}{2011} & \multicolumn{4}{|l|}{2012} & \multicolumn{4}{|l|}{2013} \\
\hline & $\mathrm{n}$ & & $(\%)$ & & $\mathrm{n}$ & & $(\%)$ & & $\mathrm{n}$ & & $(\%)$ & \\
\hline Male & 56 & & 49 & & 38 & & 33 & & 48 & & 40 & \\
\hline Female & 59 & & 51 & & 78 & & 67 & & 71 & & 60 & \\
\hline \multirow[t]{2}{*}{ Total } & 115 & & -100 & & 116 & & -100 & & 119 & & -100 & \\
\hline & Male & & Female & & Male & & Female & & Male & & Female & \\
\hline Age & $\mathrm{n}$ & $(\%)$ & $\mathrm{n}$ & $(\%)$ & $\mathrm{n}$ & $(\%)$ & $\mathrm{n}$ & $(\%)$ & $\mathrm{n}$ & $(\%)$ & $\mathrm{n}$ & $(\%)$ \\
\hline $10-19$ & 1 & 2 & 0 & 0 & 0 & 0 & 0 & 0 & 0 & 0 & 0 & 0 \\
\hline $20-29$ & 2 & 4 & 3 & 5 & 3 & 8 & 2 & 3 & 3 & 6 & 5 & 7 \\
\hline $30-39$ & 4 & 7 & 5 & 8 & 5 & 13 & 9 & 12 & 7 & 15 & 8 & 11 \\
\hline $40-49$ & 5 & 9 & 7 & 12 & 7 & 18 & 15 & 19 & 10 & 21 & 12 & 17 \\
\hline $50-59$ & 16 & 29 & 20 & 34 & 11 & 28 & 21 & 27 & 12 & 25 & 16 & 23 \\
\hline $60-69$ & 19 & 34 & 14 & 24 & 8 & 21 & 24 & 31 & 14 & 29 & 21 & 30 \\
\hline $70-79$ & 9 & 16 & 8 & 14 & 5 & 13 & 6 & 8 & 2 & 4 & 6 & 8 \\
\hline$\geq 85$ & 0 & 0 & 2 & 3 & 0 & 0 & 1 & 1 & 0 & 0 & 3 & 4 \\
\hline Total & 56 & & 59 & & 38 & & 78 & & 48 & & 71 & \\
\hline \multirow[t]{2}{*}{ Ethnicity } & Male & & Female & & Male & & Female & & Male & & Female & \\
\hline & $\mathrm{n}$ & $(\%)$ & $\mathrm{n}$ & $(\%)$ & $\mathrm{n}$ & $(\%)$ & $\mathrm{n}$ & $(\%)$ & $\mathrm{n}$ & $(\%)$ & $\mathrm{n}$ & $(\%)$ \\
\hline SEA & 40 & 67 & 36 & 45 & 30 & 79 & 43 & 70 & 37 & 77 & 53 & 75 \\
\hline African & 8 & 11 & 14 & 18 & 6 & 15 & 28 & 21 & 5 & 10 & 13 & 18 \\
\hline Mixed & 8 & 11 & 8 & 10 & 2 & 5 & 7 & 9 & 6 & 13 & 5 & 7 \\
\hline Other & - & - & 1 & 1 & - & - & - & - & - & - & - & \\
\hline Total & 56 & & 59 & & 38 & & 78 & & 48 & & 71 & \\
\hline \multirow[t]{2}{*}{ Marital status } & Male & & Female & & Male & & Female & & Male & & Female & \\
\hline & $\mathrm{n}$ & $(\%)$ & $\mathrm{n}$ & $(\%)$ & $\mathrm{n}$ & $(\%)$ & $\mathrm{n}$ & $(\%)$ & $\mathrm{n}$ & $(\%)$ & $\mathrm{n}$ & $(\%)$ \\
\hline Single & 10 & 25 & 12 & 23 & 16 & 31 & 29 & 30 & 18 & 38 & 21 & 30 \\
\hline Married & 20 & 58 & 26 & 50 & 16 & 51 & 28 & 44 & 22 & 47 & 36 & 51 \\
\hline \multirow[t]{3}{*}{ law Common } & 13 & 10 & 14 & 13 & 4 & 14 & 17 & 19 & 6 & 13 & 11 & 16 \\
\hline & 13 & 8 & 7 & 13 & 2 & 4 & 4 & 6 & 2 & 2 & 3 & 3 \\
\hline & 56 & & 59 & & 38 & & 78 & & 48 & & 71 & \\
\hline
\end{tabular}

timated that there are presently 8 million diabetics who are unaware of their condition [17]. This alarming number raises the controversial issue of screening. A recent review summarizing a consensus statement by the USPSTF (US Preventive Services Task Force: Screening for Type 2 Diabetes Mellitus) reported that diabetes screening did not reduce mortality in a population followed for 10 years [18]. However, Herman and colleagues reported that a 6-year delay in diagnosis would increase the 10-year risk for cardiovascular events by $29 \%$ [19]. The other benefits include informed approaches to individualizing glycemic targets. In addition, identifying patients at risk of developing hyperglycemia requiring admission to an AED and/or subsequent hospitalization can lead to the development and implementation of prevention strategies, which in the long term can reduces hospital admissions and health care costs. Such strategies may include better access to medical care, proper patient education, and effective communication with health care providers. In this regard, patients utilizing accident and emergency department (AED) services provide a source of high quality data.

The aim of this study therefore is to measure the occurrence of hyperglycemic events requiring emergency care and subsequent hospitalization, particularly in patients with T2DM with or without hypertension and describe the epidemiological 
Table 2. Random Blood Glucose on Admission to AED by Age in All Patients With a Hyperglycemic Event, 2011 - 2013

\begin{tabular}{llllllll}
\hline Blood glucose (mg/dL) & $180-250$ & $251-320$ & $321-390$ & $391-460$ & $461-530$ & $531-600$ \\
Age & $\mathrm{n}(\%)$ & $\mathrm{n}(\%)$ & $\mathrm{n}(\%)$ & $\mathrm{n}(\%)$ & $\mathrm{n}(\%)$ & $\mathrm{n}(\%)$ & Total \\
$18-29$ & $1(0.29)$ & - & - & - & - & - & 1 \\
$30-39$ & $9(2.57)$ & $4(1.14)$ & - & - & $3(0.86)$ & - & 16 \\
$40-49$ & $43(12.29)$ & $10(2.86)$ & $5(1.43)$ & $3(0.86)$ & $2(0.57)$ & - & 63 \\
$50-59$ & $23(6.57)$ & $34(9.71)$ & $32(9.14)$ & $20(5.71)$ & $15(4.29)$ & - & 125 \\
$60-69$ & $27(7.71)$ & $12(3.43)$ & $23(6.57)$ & $26(7.43)$ & $2(0.57)$ & $1(0.29)$ & 91 \\
$70-79$ & $25(7.14)$ & $4(1.14)$ & $5(1.43)$ & $4(1.14)$ & $2(0.57)$ & $2(0.57)$ & 42 \\
$80-89$ & $2(0.57)$ & $2(0.57)$ & $2(0.57)$ & $3(0.86)$ & $3(0.86)$ & $1(0.29)$ & 12 \\
Total & $130(37.1)$ & $66(18.9)$ & $67(19.1)$ & $56(16.0)$ & $27(7.7)$ & $4(1.1)$ & 350 \\
\hline
\end{tabular}

features for the period $2011-2013$.

\section{Methods}

The medical records of all adult patients admitted to the Sangre Grande General Hospital, a community teaching hospital of the Eastern Regional Health Authority, were reviewed, from January 1, 2010 to December 31, 2012. The hospital (UH) is a 60-bed teaching hospital attached to the University of the West Indies and the main tertiary care facility of the Eastern Regional Health Authority (ERHA). Trinidad is divided into four administrative regions for the purpose of delivering of health care. The ERHA delivers care to the eastern half of the island. The AED operates a $24 \times 7$ service, receiving referrals from both the private and public health care facilities. All adult patients ( $\geq 18$ years) with hyperglycemia presenting to the AED of the UH with clinical evidence of hyperglycemia were eligible for entry into the study. Hyperglycemia is defined as a random glucose level above $180 \mathrm{mg} /$ $\mathrm{dL}$ as recommended by the American Association of Clinical Endocrinologist (AACE) and the American Diabetes Association (ADA) $[20,21]$. In addition, a hyperglycemic crisis is defined as plasma glucose $\geq 250 \mathrm{mg} / \mathrm{dL}$ and urine + for ketones [22]. In this regard, a $5 \mathrm{~mL}$ specimen of whole blood was withdrawn from each patient using a venous access in the hand or antecubital fossa. The specimen was analyzed using an automated technique. In addition, non-comatose patients were asked to pass urine, which was tested for ketone bodies using a dipstick method. Patients currently using drugs that affect carbohydrate metabolism leading to hyperglycemia, such as corticosteroids, thiazides, sympathomimetic agents, and pentamidine, were excluded from the study [23]. In addition, all patients currently using antipsychotic drugs were also excluded from the study. Hyperglycemia with a significant increased risk of hospitalization has been reported in patients with diabetes, using antipsychotic drugs [24-27]. Appropriate demographic data and clinical presentation were collected. Trained registered nurses in the AED measured BP in accordance with the American Heart Association guidelines using an automated sphygmomanometer. Hypertension is defined using the JNC 8 classification of hypertension [27]. Costs as- sociated with laboratory and radiologic investigations, as well as pharmaceutical preparations including intravenous therapy, were collected. The costs for room and board (including services such as laundry, nutrition, nursing, and housekeeping) are calculated using the "per diem method", in which each day of hospitalization is assigned a cost determined by the Ministry of Health.

All data were expressed as mean \pm SD. Significance was set at a $\mathrm{P} \leq 0.05$. Statistical analysis included the Wilcoxon rank scores test for non-parametric distributions, ANOVA and $\chi^{2}$. Data were analyzed using SPSS-PC vs 12 for Windows (SPSS Inc., Chicago, IL, USA). The University of the West Indies Ethics Committee approved the study.

\section{Results}

Over the period 2011 - 2013, 350 eligible patients who met the entry criteria were available for analysis. The majority of patients $(230,65.7 \%)$ after initial stabilization in the AED required hospital admission. An analysis of all-cause hospital admission rate from the AED was 7.5 per 1,000 admissions annually. However, patients with T2DM and hyperglycemia accounted for a third of all admissions with a hospital admission rate of 2.8 per 1,000 admissions annually. Baseline characteristics of the 350 patients showed that there were more women $(204,59.4 \%, \mathrm{f} / \mathrm{m} 1.4: 1)$ than men $(142,40.6 \%)$ (Table 1). However, there was significant $(\mathrm{P}<0.001)$ gender disparity in 2012 and 2013. The mean age was 57 years (SD: 5 years) while the inter-quartile range was 56 years. Only $4.5 \%$ (16) of patients were newly diagnosed with T2DM, i.e. presenting for the first time with hyperglycemia. The majority of patients $(36 \%, 126)$ had T2DM for $6-10$ years and seven $(2 \%)$ had long standing T2DM ( $>20$ years). The population of Trinidad consists of two major diaspora South East Asians (SEA) and Africans both representing approximately $35 \%$ of the population respectively. There was a significant $(\mathrm{P}<0.05)$ ethnic disparity between SEA (72\%, 95\% CI $64-80)$ and Africans $(17 \%, 95 \%$ CI $12-23)$. The majority of AEV $(166,47.4 \%)$ occurred in a window between 600 and 1,000 h. The remaining 184 patients presented almost evenly during all other times. The majority of patients were ambulatory; however, only four 


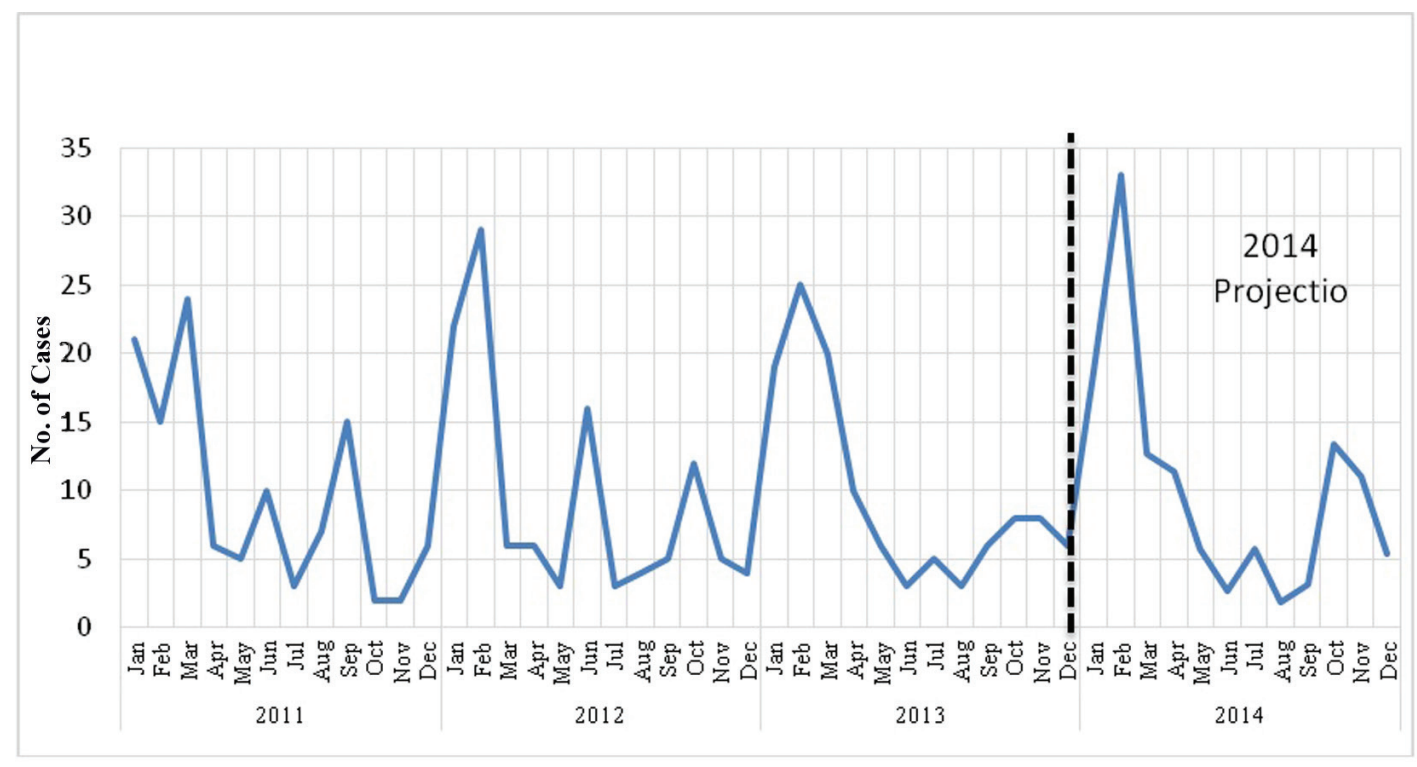

Figure 1. Time series of number of cases of hyperglycemia by month for the years and the forecast for 2014 .

$(1.1 \%)$ patients had a Glasgow coma score of $<7$. On admission, all patients had a random plasma glucose assessment. Based on random blood plasma glucose on admission to the AED, almost two-thirds $(220,63 \%)$ of the patients were presenting in a hyperglycemic crisis (Table 2). It was interesting to find that at age of 60 years, the number of hyperglycemic events declined with age.

Hyperglycemic events were plotted over time in months in order to determine seasonal effects (Fig. 1). We defined seasonal variation as cyclic changes in disease occurrence or disease severity over the course of a calendar year [28, 29]. We hypothesize that there was an increase in the number of cases in February compared with the remainder of the year. Occurrence was measured as a count of cases per unit of time although population data were available. The outcome measure was the peak-to-low ratio, interpreted as a measure of relative risk (RR) that compares the month with the highest incidence (peak) with the month with the lowest incidence (low or trough). To conduct this analysis, we used the freely available programmed spreadsheet, Episheet [30], which provides a graphical presentation of seasonal variation, and estimates the time of the peak, the peak-to-low ratio, and a confidence interval for the latter. Hence we established a seasonal variation with the time of the peak in February, and the peak-to-low ratio was $4.6(95 \%$ CI 2.1 - 9.4). In addition, the statistical package SPSS version 12.0 for Windows was used to develop an autoregressive integrated moving average (ARIMA) model to forecast hyperglycemic events for 2014 (Fig. 1) [31, 32]. The ARIMA model was analyzed with the Box-Jenkins approach, a useful tool for analyzing non-stationary time-series data containing seasonal trends [33].

Using the new JNC 8 classification, 192 (59\%) patients also had uncontrolled hypertension $(>140 / 90)$. In addition, $25 \%$ of patients presented with anemia $(\mathrm{Hb}<10 \mathrm{~g} / \mathrm{dL})$ and $18 \%$ with tachycardia. It was also interesting that $<1 \%$ of all the admissions was associated with sepsis.

\section{Discussion}

There are several important findings of this study. Primarily 350 patients with hyperglycemia were seen and treated in the AED over the period 2010 - 2013, with only 4\% attributed to new onset diabetes and 1\% to infection. Two-thirds of these patients were subsequently transferred from the AED to hospital for further care. Thus it is emphasized that hyperglycemia continues to be a significant burden on health care facilities in Trinidad, a small developing country. Hyperglycemia in hospitalized patients, irrespective of its cause, is unequivocally associated with adverse outcomes [34-43]. Lebovitz reports that recent evidence has accumulated, indicating that isolated postprandial hyperglycemia (i.e., 2 -h postprandial levels $>140$ $\mathrm{mg} / \mathrm{dL}$ and fasting levels $<110 \mathrm{mg} / \mathrm{dL}$ ) is common and is an independent clinically significant risk factor for CVD [44]. Prospective epidemiologic studies [45-50] have illustrated a correlation between the risk for CVD and either plasma glucose levels or HbAlc values.

In contrast, in some developed countries, the increasing intensity of diabetes management driven by a wider array of available drugs and strategies has resulted in reduced hyperglycemic emergency rates but higher hypoglycemic rates [51]. Apart from being preventable, the majority of patients (194, $96 \%$ ) had long standing T2DM (6 - 10 years). Glycemic control is significantly associated with age, race/ethnicity, duration of diabetes, type and number of medications taken, obesity, psychological variables, and family support [52-63]. In addition, poor medical care, lack of education, non-compliance of patients or access to care problems all contribute to poor glycemic control, all of which are relevant to resource poor countries. The AACE/American College of Endocrinology Diabe- 
tes guidelines has responded to this problem by providing an algorithm to assist primary care physicians, endocrinologists, and others in the management of adult, non-pregnant patients with T2DM [64]. Developing countries may also consider adopting this approach.

Another important finding of the study was the significant difference $(\mathrm{P}=0.001)$ in the occurrence of hyperglycemic events among women (204, 59.4\%, f/m 1.4:1) compared with men $(142,40.6 \%)$. Other studies suggest a gender disparity of $10-15 \%$, women being the dominant group $[65,66]$. The under-recognition of the risk of hyperglycemia in women with T2DM may lead to less effective prevention, clinical care, and outcomes. Furthermore, self-awareness in women and identification of gaps in attaining glycemic control needs more attention, which should result in better prevention of hyperglycemic events.

In order to estimate the cost associated with hyperglycemic events, we first calculated the average duration of hospitalization, i.e. 3 days. This translated into a $27 \%$ bed utilization rate on the medical wards during the study period. Using the estimated per diem cost for the treatment of T2DM provided by the Ministry of Health, the cost associated with treating hyperglycemia for the study period was 1.5 million (USD). This cost did not include treatment for comorbidities and was not adjusted for yearly inflation. The cost to the patient including intangible costs (pain, anxiety, inconvenience and generally lower quality of life, etc.) and reduced productivity was not calculated. Nevertheless, this estimate highlights the economic burden of treating just one aspect of diabetes in small developing economy, and necessitates immediate action.

We demonstrated for the first time in a Trinidadian population a temporal association of hyperglycemic events requiring AED visits. In the first instance approximately $50 \%$ of the patients presented during the period 600 and $1,000 \mathrm{~h}$. This observation is in agreement with previous reports on circadian glucose profile $[67,68]$. These excessive post-breakfast glucose excursions may correspond to the so-called "extended dawn phenomenon", which is characterized by the fact that the glucose tolerance is worse in the early morning than at any other time of the day [69]. The dawn and extended dawn phenomena behave conjointly since they depend on an increase in both hepatic glucose output/neoglycogenesis and peripheral insulin resistance in the early morning period [70, 71], which if accumulated over time may lead to a hyperglycemic crisis. In addition, we established a seasonal variation in hyperglycemia events (peak-to-low ratio 4.6, 95\% CI 2.1 -9.4). Lang showed that in patients with diabetes receiving treatment, the blood pressure, preprandial glucose, A1C, and LDL cholesterol varied seasonally, with higher values in the winter and lower values in the summer. Specifically preprandial glucose was inversely correlated with the monthly mean climate temperature [72]. Trinidad is situated at longitude $61^{\circ}$ and latitude $11^{\circ}$, and is a tropical island with marginal variations in temperature and hence with serum 25-hydroxyvitamin D3. Contrary to Lang, the most likely explanation in our setting my in fact be attributed to festivals influencing patient lifestyle. Trinidad is a multireligious society; however, Christians represent approximately $50 \%$ of the population. Christmas is a very popular celebration with two consecutive public holidays. Traditional foods pre- pared at this time consist mainly of carbohydrates (breads and pastels), pastry (black cake) and sugar sweetened beverages (sorrel). Christmas is immediately followed by another major celebration Carnival, also spanning 2 days. Alcohol consumption is also increased at these times. Therefore, both festivals may play a role in the results of this study.

To our knowledge, prior studies have not evaluated national trends in both hyperglycemic and hypoglycemic complications of T2DM. The patients we studied did not have good glycemic control, as indicated by their HbA1c, and therefore may be more likely to be part of the study.

We focused on events that were chiefly responsible for hospital admissions, and some hyperglycemic events may be minor and easily reversible in a primary care setting. Hence we may have underestimated the true occurrence of hyperglycemia. Our analyses have several additional limitations. We were unable to fully account for trends in T2DM prevalence over time or explicitly define the denominator of patients with T2DM, but our intent was to describe the overall burden of these hospitalizations on the health care system.

In conclusion, hospital admission rates for hyperglycemia from 2010 to 2013 are high and efforts to reduce these hospitalizations, especially among woman and younger adults, are urgently needed.

\section{References}

1. Kannel WB, McGee DL. Diabetes and cardiovascular disease. The Framingham study. JAMA. 1979;241(19):20352038.

2. Kagan A, Popper JS, Rhoads GG. Factors related to stroke incidence in Hawaii Japanese men. The Honolulu Heart Study. Stroke. 1980;11(1):14-21.

3. Trinidad and Tobago National Census 2011, Government of the republic of Trinidad and Tobago, CSO.

4. Ministry of Health, Republic of Trinidad and Tobago, Ministry of Health stratergic plan, 2012-2016.

5. Stamler J, Vaccaro O, Neaton JD, Wentworth D. Diabetes, other risk factors, and 12-yr cardiovascular mortality for men screened in the Multiple Risk Factor Intervention Trial. Diabetes Care. 1993;16(2):434-444.

6. Laakso M, Lehto S. Epidemiology of macrovascular disease in diabetes. Diabetes Rev. 1997;5:294-315.

7. Most RS, Sinnock P. The epidemiology of lower extremity amputations in diabetic individuals. Diabetes Care. 1983;6(1):87-91.

8. Solomon S, Affan AM, Gopie P, Noel J, Rahman R, Richardson R, Ramkisson S, et al. Taking the next step in 2005, the year of the diabetic foot. Prim Care Diabetes. 2008;2(4):175-180.

9. Intensive blood-glucose control with sulphonylureas or insulin compared with conventional treatment and risk of complications in patients with type 2 diabetes (UKPDS 33). UK Prospective Diabetes Study (UKPDS) Group. Lancet. 1998;352(9131):837-853.

10. The effect of intensive treatment of diabetes on the development and progression of long-term complications in insulin-dependent diabetes mellitus. The Diabetes Con- 
trol and Complications Trial Research Group. N Engl J Med. 1993;329(14):977-986.

11. Sowers JR, Epstein M. Diabetes mellitus and associated hypertension, vascular disease, and nephropathy. An update. Hypertension. 1995;26(6 Pt 1):869-879.

12. Anderson EA, Hoffman RP, Balon TW, Sinkey CA, Mark AL. Hyperinsulinemia produces both sympathetic neural activation and vasodilation in normal humans. J Clin Invest. 1991;87(6):2246-2252.

13. Perlstein TS, Gerhard-Herman M, Hollenberg NK, Williams GH, Thomas A. Insulin induces renal vasodilation, increases plasma renin activity, and sensitizes the renal vasculature to angiotensin receptor blockade in healthy subjects. J Am Soc Nephrol. 2007;18(3):944-951.

14. Purnell JQ, Hokanson JE, Marcovina SM, Steffes MW, Cleary PA, Brunzell JD. Effect of excessive weight gain with intensive therapy of type 1 diabetes on lipid levels and blood pressure: results from the DCCT. Diabetes Control and Complications Trial. JAMA. 1998;280(2):140146.

15. Brownlee M. The pathobiology of diabetic complications: a unifying mechanism. Diabetes. 2005;54(6):16151625 .

16. Ceriello A. Controlling oxidative stress as a novel molecular approach to protecting the vascular wall in diabetes. Curr Opin Lipidol. 2006;17(5):510-518.

17. United States Centers for Disease Control and Prevention (CDC) National Diabetes Statistics Report, 2014. http:// www.cdc.gov/diabetes/pubs/statsreport14/national-diabetes-report-web.pdf Accessed July 8, 2015.

18. Selph S, Dana T, Blazina I, Bougatsos C, Patel H, Chou R. Screening for type 2 diabetes mellitus: a systematic review for the U.S. Preventive Services Task Force. Ann Intern Med. 2015;162(11):765-776.

19. Herman WH, Ye W, Griffin SJ, Simmons RK, Davies MJ, Khunti K, Rutten GE, et al. Early Detection and Treatment of Type 2 Diabetes Reduce Cardiovascular Morbidity and Mortality: A Simulation of the Results of the Anglo-Danish-Dutch Study of Intensive Treatment in People With Screen-Detected Diabetes in Primary Care (ADDITION-Europe). Diabetes Care. 2015;38(8):14491455.

20. American College of Endocrinology and American Diabetes Association Consensus statement on inpatient diabetes and glycemic control. Diabetes Care. 2006;29(8):19551962.

21. Standards of medical care in diabetes--2008. Diabetes Care. 2008;31(Suppl 1):S12-54.

22. Kitabchi AE, Umpierrez GE, Miles JM, Fisher JN. Hyperglycemic crises in adult patients with diabetes. Diabetes Care. 2009;32(7):1335-1343.

23. Lipscombe LL, Levesque L, Gruneir A, Fischer HD, Juurlink DN, Gill SS, Herrmann N, et al. Antipsychotic drugs and hyperglycemia in older patients with diabetes. Arch Intern Med. 2009;169(14):1282-1289.

24. Newcomer JW. Second-generation (atypical) antipsychotics and metabolic effects: a comprehensive literature review. CNS Drugs. 2005;19(Suppl 1):1-93.

25. Scheen AJ, De Hert MA. Abnormal glucose metabolism in patients treated with antipsychotics. Diabetes Metab. 2007;33(3):169-175.

26. Avella J, Wetli CV, Wilson JC, Katz M, Hahn T. Fatal olanzapine-induced hyperglycemic ketoacidosis. Am J Forensic Med Pathol. 2004;25(2):172-175.

27. James PA, Oparil S, Carter BL, Cushman WC, Dennison-Himmelfarb C, Handler J, Lackland DT, et al. 2014 evidence-based guideline for the management of high blood pressure in adults: report from the panel members appointed to the Eighth Joint National Committee (JNC 8). JAMA. 2014;311(5):507-520.

28. Dowell SF. Seasonal variation in host susceptibility and cycles of certain infectious diseases. Emerg Infect Dis. 2001;7(3):369-374.

29. Grassly NC, Fraser C. Seasonal infectious disease epidemiology. Proc Biol Sci. 2006;273(1600):2541-2550.

30. Box G, Pierce DA. Distribution of residual autocorrelations in autoregressive-integrated moving average timeseries models. J Am Stat Ass 1970;65:1509-1526.

31. Box G, Jenkins G. Time series analysis: Forecasting and Control, Holden-Day: San Francisco; 1976.

32. Chowell G, Sanchez F. Climate-based descriptive models of dengue fever: the 2002 epidemic in Colima, Mexico. J Environ Health. 2006;68(10):40-44, 55.

33. Checkley W, Epstein LD, Gilman RH, Figueroa D, Cama RI, Patz JA, Black RE. Effect of El Nino and ambient temperature on hospital admissions for diarrhoeal diseases in Peruvian children. Lancet. 2000;355(9202):442450 .

34. van den Berghe $G$, Wouters P, Weekers F, Verwaest C, Bruyninckx F, Schetz M, Vlasselaers D, et al. Intensive insulin therapy in critically ill patients. N Engl J Med. 2001;345(19):1359-1367.

35. Malmberg K, Norhammar A, Wedel H, Ryden L. Glycometabolic state at admission: important risk marker of mortality in conventionally treated patients with diabetes mellitus and acute myocardial infarction: long-term results from the Diabetes and Insulin-Glucose Infusion in Acute Myocardial Infarction (DIGAMI) study. Circulation. 1999;99(20):2626-2632.

36. Malmberg K. Prospective randomised study of intensive insulin treatment on long term survival after acute myocardial infarction in patients with diabetes mellitus. DIGAMI (Diabetes Mellitus, Insulin Glucose Infusion in Acute Myocardial Infarction) Study Group. BMJ. 1997;314(7093):1512-1515.

37. Furnary AP, Zerr KJ, Grunkemeier GL, Starr A. Continuous intravenous insulin infusion reduces the incidence of deep sternal wound infection in diabetic patients after cardiac surgical procedures. Ann Thorac Surg. 1999;67(2):352-360; discussion 360-352.

38. Latham R, Lancaster AD, Covington JF, Pirolo JS, Thomas CS, Jr. The association of diabetes and glucose control with surgical-site infections among cardiothoracic surgery patients. Infect Control Hosp Epidemiol. 2001;22(10):607-612.

39. Sala J, Masia R, Gonzalez de Molina FJ, Fernandez-Real JM, Gil M, Bosch D, Ricart W, et al. Short-term mortality of myocardial infarction patients with diabetes or hy- 
perglycaemia during admission. J Epidemiol Community Health. 2002;56(9):707-712.

40. Furnary AP, Gao G, Grunkemeier GL, Wu Y, Zerr KJ, Bookin SO, Floten HS, et al. Continuous insulin infusion reduces mortality in patients with diabetes undergoing coronary artery bypass grafting. J Thorac Cardiovasc Surg. 2003;125(5):1007-1021.

41. Krinsley JS. Effect of an intensive glucose management protocol on the mortality of critically ill adult patients. Mayo Clin Proc. 2004;79(8):992-1000.

42. Pittas AG, Siegel RD, Lau J. Insulin therapy for critically ill hospitalized patients: a meta-analysis of randomized controlled trials. Arch Intern Med. 2004;164(18):20052011.

43. Ishihara M, Kojima S, Sakamoto T, Asada Y, Tei C, Kimura K, Miyazaki S, et al. Acute hyperglycemia is associated with adverse outcome after acute myocardial infarction in the coronary intervention era. Am Heart J. 2005;150(4):814-820.

44. Lebovitz HE. Effect of the postprandial state on nontraditional risk factors. Am J Cardiol. 2001;88(6A):20H-25H.

45. Standl E,Balletshofer B,Dahl B, et al. Predictors of 10year macrovascular and overall mortality in patients with NIDDM: the Munich General Practitioner Project. Diabetologia. 1996;391:540-545.

46. Barrett-Connor E, Ferrara A. Isolated postchallenge hyperglycemia and the risk of fatal cardiovascular disease in older women and men. The Rancho Bernardo Study. Diabetes Care. 1998;21(8):1236-1239.

47. Rodriguez BL, Lau N, Burchfiel CM, Abbott RD, Sharp DS, Yano K, Curb JD. Glucose intolerance and 23-year risk of coronary heart disease and total mortality: the Honolulu Heart Program. Diabetes Care. 1999;22(8):12621265.

48. Shaw JE, Hodge AM, de Courten M, Chitson P, Zimmet PZ. Isolated post-challenge hyperglycaemia confirmed as a risk factor for mortality. Diabetologia. 1999;42(9):10501054

49. Tominaga M, Eguchi H, Manaka H, Igarashi K, Kato T, Sekikawa A. Impaired glucose tolerance is a risk factor for cardiovascular disease, but not impaired fasting glucose. The Funagata Diabetes Study. Diabetes Care. 1999;22(6):920-924.

50. Lowe LP, Liu K, Greenland P, Metzger BE, Dyer AR, Stamler J. Diabetes, asymptomatic hyperglycemia, and 22-year mortality in black and white men. The Chicago Heart Association Detection Project in Industry Study. Diabetes Care. 1997;20(2):163-169.

51. Lipska KJ, Ross JS, Wang Y, Inzucchi SE, Minges K, Karter AJ, Huang ES, et al. National trends in US hospital admissions for hyperglycemia and hypoglycemia among Medicare beneficiaries, 1999 to 2011 . JAMA Intern Med. 2014;174(7):1116-1124.

52. Bruce DG, Davis WA, Davis TM. Glycemic control in older subjects with type 2 diabetes mellitus in the Fremantle Diabetes Study. J Am Geriatr Soc. 2000;48(11):14491453.

53. Fox KM, Gerber Pharmd RA, Bolinder B, Chen J, Kumar S. Prevalence of inadequate glycemic control among patients with type 2 diabetes in the United Kingdom general practice research database: A series of retrospective analyses of data from 1998 through 2002. Clin Ther. 2006;28(3):388-395.

54. Benoit SR, Fleming R, Philis-Tsimikas A, Ji M. Predictors of glycemic control among patients with Type 2 diabetes: a longitudinal study. BMC Public Health. 2005;5:36.

55. Chiu CJ, Wray LA. Factors predicting glycemic control in middle-aged and older adults with type 2 diabetes. Prev Chronic Dis. 2010;7(1):A08.

56. Blaum CS, Velez L, Hiss RG, Halter JB. Characteristics related to poor glycemic control in NIDDM patients in community practice. Diabetes Care. 1997;20(1):7-11.

57. Ali MK, McKeever Bullard K, Imperatore G, Barker L, Gregg EW. Characteristics associated with poor glycemic control among adults with self-reported diagnosed diabetes--National Health and Nutrition Examination Survey, United States, 2007-2010. MMWR Morb Mortal Wkly Rep. 2012;61(Suppl):32-37.

58. Hartz A, Kent S, James P, Xu Y, Kelly M, Daly J. Factors that influence improvement for patients with poorly controlled type 2 diabetes. Diabetes Res Clin Pract. 2006;74(3):227-232.

59. Rose M, Fliege H, Hildebrandt M, Schirop T, Klapp BF. The network of psychological variables in patients with diabetes and their importance for quality of life and metabolic control. Diabetes Care. 2002;25(1):35-42.

60. Harris MI, Eastman RC, Cowie CC, Flegal KM, Eberhardt MS. Racial and ethnic differences in glycemic control of adults with type 2 diabetes. Diabetes Care. 1999;22(3):403-408.

61. Mayberry LS, Osborn CY. Family support, medication adherence, and glycemic control among adults with type 2 diabetes. Diabetes Care. 2012;35(6):1239-1245.

62. Nichols GA, Hillier TA, Javor K, Brown JB. Predictors of glycemic control in insulin-using adults with type 2 diabetes. Diabetes Care. 2000;23(3):273-277.

63. Shani M, Taylor TR, Vinker S, Lustman A, Erez R, Elhayany A, Lahad A. Characteristics of diabetics with poor glycemic control who achieve good control. J Am Board Fam Med. 2008;21(6):490-496.

64. Rodbard HW, Jellinger PS, Davidson JA, Einhorn D, Garber AJ, Grunberger G, Handelsman Y, et al. Statement by an American Association of Clinical Endocrinologists/ American College of Endocrinology consensus panel on type 2 diabetes mellitus: an algorithm for glycemic control. Endocr Pract. 2009;15(6):540-559.

65. Raum E, Kramer HU, Ruter G, Rothenbacher D, Rosemann T, Szecsenyi J, Brenner H. Medication non-adherence and poor glycaemic control in patients with type 2 diabetes mellitus. Diabetes Res Clin Pract. 2012;97(3):377-384.

66. Yousefzadeh G, Shokoohi M, Najafipour H. Inadequate control of diabetes and metabolic indices among diabetic patients: A population based study from the Kerman Coronary Artery Disease Risk Study (KERCADRS). Int J Health Policy Manag. 2015;4(5):271-277.

67. Ollerton RL, Playle R, Ahmed K, Dunstan FD, Luzio SD, Owens DR. Day-to-day variability of fasting plasma glu- 
cose in newly diagnosed type 2 diabetic subjects. Diabetes Care. 1999;22(3):394-398.

68. Monnier L, Colette C, Rabasa-Lhoret R, Lapinski H, Caubel C, Avignon A, Boniface H. Morning hyperglycemic excursions: a constant failure in the metabolic control of non-insulin-using patients with type 2 diabetes. Diabetes Care. 2002;25(4):737-741.

69. Monnier L, Colette C, Dunseath GJ, Owens DR. The loss of postprandial glycemic control precedes stepwise deterioration of fasting with worsening diabetes. Diabetes Care. 2007;30(2):263-269.
70. Boden G, Chen X, Urbain JL. Evidence for a circadian rhythm of insulin sensitivity in patients with NIDDM caused by cyclic changes in hepatic glucose production. Diabetes. 1996;45(8):1044-1050.

71. Perriello G, Pampanelli S, Del Sindaco P, Lalli C, Ciofetta M, Volpi E, Santeusanio F, et al. Evidence of increased systemic glucose production and gluconeogenesis in an early stage of NIDDM. Diabetes. 1997;46(6):1010-1016.

72. Liang WW. Seasonal changes in preprandial glucose, A1C, and blood pressure in diabetic patients. Diabetes Care. 2007;30(10):2501-2502. 